\title{
Ambivalencias en la escucha de la tortura en Chile: implicancias clínicas y sociales
}

\author{
Ambivalences in the listening of torture in Chile: clinical and social implications
}

\author{
Germán Morales \\ Marcela Cornejo \\ Pontificia Universidad Católica de Chile
}

(Rec: 14 de septiembre de 2012 / Acept: 12 de diciembre de 2012)

\begin{abstract}
Resumen
Los resultados presentados surgen del análisis de dos instancias en las que se escuchó acerca de la tortura ocurrida en Chile durante la Dictadura Militar: una investigación realizada con profesionales de la Comisión Nacional sobre Prisión Política, y grupos psicoterapéuticos realizados con personas que luego de declarar ante esta Comisión, fueron derivados a atención psicológica. Se recogieron relatos de vida con 22 profesionales de la Comisión, y se realizaron 4 grupos psicoterapéuticos ( 2 de mujeres y 2 de hombres) con 29 personas. En ambos casos, la escucha se centró en experiencias que apelaron a lo traumático, determinando la emergencia de ambivalencias, tanto respecto a emociones surgidas, como de la dimensión institucional determinada por el hecho que ambas instancias hayan sido realizadas asociadas a la Comisión. Los análisis permiten comprender efectos que la escucha de la tortura genera tanto a nivel individual como social.

Palabras clave: Tortura, identificación ambivalente, Comisión Nacional sobre Prisión Política y Tortura, grupos psicoterapéuticos.
\end{abstract}

\begin{abstract}
The results presented are derived from the analysis of two instances in which individuals gave their testimonies of torture during the military dictatorship in Chile: a study conducted with professionals from the Chilean National Commission on Political Imprisonment and Torture, and psychotherapeutic groups for people who were referred to psychological treatment after declaring before said commission. The life stories of 22 professionals working for the Commission were documented, and 4 psychotherapy groups comprising 29 people in total were set up ( 2 for men and 2 for women)". In both cases, the listening sessions focused on experiences of traumatic events, which resulted in the emergence of ambivalences regarding the emotions felt and the institutional dimension due to the fact that both listening instances were carried out in association with the Commission. The analyses make it possible to understand the effects that the listening of torture generates at an individual and a social level.

Key words: Torture, ambivalent identification, Chilean National Commission on Political Imprisonment and Torture, psychotherapy groups
\end{abstract}

\section{Introducción}

El golpe de Estado ocurrido en Chile el 11 de septiembre de 1973 y la dictadura que duró 17 años, son acontecimientos que han impactado la historia del país y las historias personales y familiares de numerosos hombres y mujeres. Se trata de una ruptura de carácter traumático, tanto para la historia colectiva como para la subjetividad de todos los chilenos, especialmente para aquellos que fueron víctimas directas de las violaciones a los derechos humanos ocurridas en este período.

Durante la dictadura y posterior a ella, la prisión política y la tortura (en adelante PPT) no fueron reconocidas

Nota autor: Este trabajo ha recibido financiamiento del Proyecto FONDECYT N¹070855 "Del Testimonio al Relato de Vida: Procesos Elaborativos en Profesionales de la Comisión Nacional de Prisión Política y Tortura". Algunas de estas reflexiones fueron presentadas en el "Colloque International et interdisciplinaire: Violencepolitique, traumatisme, processusd'élaboration et de création”, Louvain, Bélgica, mayo de 2009.

Correspondencia: Germán Morales, Escuela de Psicología, Pontificia Universidad Católica de Chile.Vicuña Mackenna 4860, Macul, Santiago, Chile. Email: gpmorale@uc.cl.

Marcela Cornejo, Escuela de Psicología, Pontificia Universidad Católica de Chile. Vicuña Mackenna 4860, Macul, Santiago, Chile. E-mail: marcela@uc.cl. 
oficialmente como parte de la historia del país. En este período, los testimonios de las víctimas fueron silenciados, puestos en duda y clandestinizados, lo que no ha permito reconstruir una memoria histórica del país con respecto a los hechos de violencia de nuestro pasado reciente.

En la transición democrática post dictadura, tres instancias promovidas por el Estadode Chile han sido puestas en marcha en el objetivo de promover la reconciliación nacional y conocer la verdad sobre lo ocurrido: en 1991, la Comisión Nacional de Verdad y Reconciliación; en 2001, la Mesa de Diálogo; y en 2003 la Comisión Nacional sobre Prisión Política y Tortura. Estas iniciativas, como otras comisiones de verdad y reconciliación en el mundo, tuvieron como objetivo principal la construcción de una verdad histórica compartida respecto de los hechos que ocurrieron, reconociendo las violaciones a los derechos humanos cometidas y determinando líneas directrices para políticas de reparación respecto de las víctimas (Hamber, 2000; Van der Merwe, 2002).

En 1991 se hace público el informe de la Comisión Nacional de Verdad y Reconciliación, el que identifica más de 3.200 personas que fueron objeto de represión política con causa de muerte y en donde el Estado chileno, a través de agentes trabajando bajo sus órdenes, fue el responsable. En 2001 se constituye la Mesa de Diálogo, con la participación de representantes de las iglesias, del mundo académico, de las fuerzas armadas, de abogados y agrupaciones de derechos humanos, con el objetivo de establecer ciertos acuerdos respecto a los hechos del pasado y principalmente esclarecer el paradero de los detenidos desaparecidos.

En 2003, al conmemorar 30 años del golpe de estado contra el gobierno de Salvador Allende, se crea la Comisión Nacional sobre Prisión Política y Tortura (en adelante CNPPT), dentro del programa del gobierno para trabajar la problemáticas de derechos humanos bajo el lema "no hay mañana sin ayer". Esta comisión tuvo por objetivo ocuparse de los "sobrevivientes", de las víctimas de prisión política y tortura durante la dictadura, en donde el Estado de Chile o agentes a su servicio fueron los responsables.La CNPPT recibió el testimonio de 35.868 personas y calificó 27.255 casos como personas víctimas de PPT (Informe CNPPT, 2004) ${ }^{1}$.

La CNPPT y su Informe impactaron a la sociedad chilena en su conjunto (Cárdenas, Páez, Bilbao, Aronoso, Asúny

\footnotetext{
En 2011, la Comisión Asesora Presidencial para la Calificación de Detenidos Desaparecidos, Ejecutados Políticos y Víctimas de Prisión Política y Tortura, elabora un informe que incluye 31.841 nuevas solicitudes de calificación de personas que declaran haber sido víctimas de PPT, de las cuales 9.795 fueron calificadas.
}

Fernández, 2011), a las personas que acudieron a declarar a la Comisión (Riquelme y Cruz, 2005), así como a los profesionales que trabajaron en esta Comisión recogiendo los testimonios de los declarantes (Cornejo, Morales, Kovalskysy Sharim, en prensa).

El presente trabajo tiene como objetivo hacer una lectura de la escucha de la tortura que realizaron los profesionales de la CNPPT, relacionándola con lo expresado por las víctimas de la tortura, que luego de declarar en la Comisión recibieron ayuda psicológica engrupos terapéuticos. Tanto en el caso de los profesionales de la CNPPT, como en el de los pacientes atendidos luego de su declaración en la CNPPT, al tratarse de la escucha de experiencias que apelan a lo traumático surgieron ambivalencias, las que son analizadas desde ciertas tensiones que se establecen entre ambas instancias y que permiten comprender los efectos que la escucha de estas experiencias genera, tanto a nivel individual como social.

\section{Consecuencias de la prisión política y la tortura}

Prisión política y tortura fueron prácticas de represión masivas y sistemáticas, implementadas como políticas de Estado en Chile durante la dictadura entre 1973 y 1990 (Informe CNPPT, 2004). El objetivo fue anular a los disidentes al régimen mediante el daño infringido a estos y sus familias y la amenaza hacia el resto de la sociedad (Lira y Castillo, 1991), instaurando la desconfianza, el escepticismo, la rigidez y la violencia como formas a adoptar en la resolución de los conflictos colectivos (Barreto y Borja, 2007). El dolor, pánico y angustia generados por la tortura dan cuenta de una dimensión siniestra de esta experiencia que no encuentra representación mental homologable, determinando desestructuración no solo a nivel psíquico sino que también identitario, emocional, corporal, en las relaciones sociales y los sistemas de valores (Puget, 2006).

En este sentido, la tortura puede ser entendida como una experiencia de carácter traumático. El concepto de traumatización extrema (Bettelheim, 1981; Lira, Becker y Castillo, 1991), reconoce la especificidad social en el trauma, apuntando específicamente a dimensión de intencionalidad contenida en este y su condición de situación extrema, ya que busca determinadamente la destrucción - personal y políticade quien la recibe. Desde las conceptualizaciones relativas al trauma psicosocial propuestas por Martín-Baró (1988), se alude a un trauma cuya etiología es social, contextual e histórica, donde los eventos traumáticos afectan el tipo de relaciones sociales que se establecen. El daño psíquico producido por la violencia institucionalizada a personas 
singulares -las víctimas directas- se constituye en una experiencia límite, dada la inermidad y exposición absoluta a la acción de terceros cuyo objetivo es su destrucción no solo física sino que psicológica. Considerando que este tipo de acciones corresponden a un diseño estratégico de control político, sus efectos se extienden inevitablemente a los miembros de la sociedad en su conjunto, a las instituciones que regulan la vida ciudadana y a las normas que rigen la convivencia (Lira y Castillo, 1991), dejando su impronta de amenaza y miedo como mecanismos de control social, definiendo un contexto que dejará profundas huellas en las relaciones sociales.

Desde esta perspectiva, las consecuencias de la tortura no pueden ser concebidas como "cuadros psicopatológicos", ya que simultáneamente representan expresiones concretas del conflicto social y político que se manifiesta tanto en el psiquismo individual como en la subjetividad social. Las consecuencias por tanto, de PPT son posibles de identificar tanto a nivel individual (sintomatología aguda, consecuencias en el ámbito físico, sexual, cognitivo, emocional y existencial); en los entornos cercanos a las víctimas (familias, hijos, pareja); y finalmente en la sociedad en su conjunto, desarticulando redes sociales, estructuras de participación colectiva, llevando a una desintegración y fragmentación social (Cornejo, Rojas, Buzzoni, Mendoza, Concha y Cabach, 2007).

Otra característica importante de las consecuencias de las experiencias traumáticas es que no pueden ser consideradas como parte del pasado, sino son vivenciadas por las personas afectadas en el presente. Esto, debido a que la temporalidad es afectada dejando de ser un referente organizador, y además a que el no reconocimiento del daño, el horror y la amenaza mantenidos en el tiempo constituyen la experiencia traumática, interfiriendo en el proceso de construcción de la subjetividad (Castillo y Morales, 2011). El trauma queda así congelado en el tiempo, en un presente eterno que atrapa y se repite constantemente.

\section{Grupos terapéuticos con pacientes traumatizados en ILAS}

El Instituto Latinoamericano de Salud Mental y Derechos Humanos (ILAS) es una organización no gubernamental chilena que trabaja hasta la fecha en la atención psicoterapéutica de personas que fueron víctimas de represión política durante la dictadura militar. Además, ILAS ha desarrollado investigaciones asociadas a temáticas relativas al trauma y la violencia política, prestando asesorías en Latinoamérica y África a equipos que trabajan en estos temas.

Posterior a la CNPPT, ILAS implementó grupos terapéuticos con hombres y mujeres que dieron su testimonio a la Comisión (la separación por género se debió a que tanto hombres como mujeres sufrieron tortura sexual, y en este sentido la homogeneidad en los grupos permitió una mayor apertura de estas experiencias traumáticas) (Castillo y Díaz, 2007). Estas personas señalaron que antes de la Comisión, nunca había hablado de su experiencia, lo que debe ser entendido en el sentido de no haber expresado antes en espacios públicos legitimados sus experiencias traumáticas. Las personas víctimas de PPT habrían quedado posterior a estas experiencias "clandestinizados", intentando no ser vistos, sin reunirse ni hablar de estas experiencias para que no se sospechara de ellas, intentando retomar su vida cotidiana. Se podría entender su situación como una "animación suspendida" (Castillo y Morales, 2011) en el sentido que hasta antes de dar su testimonio en la Comisión, quedaron en suspenso. Al testimoniar en la Comisión, reabrieron aquello clandestinizado, lo cual significó remover sus experiencias, volver a hacerlas realidad en el presente, lo que determinó fuertes sentimientos de angustia, trastornos somáticos, cuadros depresivos, lo cual los hizo requerir ayuda terapéutica por lo que fueron derivados por la Comisión a ILAS (Morales, Castillo, Aguilar y Díaz, 2005).Ya que desde el silencio era el cuerpo el lugar de memoria, la psicoterapia fue un proceso de recuperar la palabra, y recuperarla con otros habían vivido esta experiencia (Castillo y Díaz, 2007; Castillo y Morales, 2011).

Por ello, el espacio terapéutico grupal es una modalidad privilegiada en el tratamiento depacientes traumatizados extremos. Dado la subjetividad dañada de las personas víctimas de PPT, era necesario reconstruir en el espacio intersubjetivo, creado portodos los miembros del grupo y por los terapeutas, un espacio que contuviera y validara las sensaciones vividas, posibilitando su simbolización y que así pasen a ocupar el lugar de recuerdo en el pasado (Castillo y Díaz, 2010; Castillo y Morales, 2011).

El encuadre grupal construido, permitió un "holding adecuado" (Winnicott, 1956), permitiendo hablar de lo que no habían contado durante años, y así trabajar lo que Winnicott (1954) denominaun "estado de regresión a la dependencia", facilitando la re-vivencia de las primeras etapas, lo que permitiría descongelar el trauma (la tortura) en un medio protegido (Castillo y Díaz, 2010; Castillo y Morales, 2011). 
Así la sesión terapéutica grupal se da en el espacio potencial, se crea el escenario que facilita el encuentro "entre" diversas personas, entre diversos discursos, entre diversos gestos, entre lo interno y lo externo (Castillo, 2009). Es posible afirmar que este espacio potencial no se había dado antes, se da en el aquí y el ahora del espacio terapéutico grupal, posibilitando la experiencia de la mutualidad.

La terapia grupal analítica genera un escenario en el que las matrices relacionales, que en su momento fueron constitutivas de cada psiquismo, intentan recrearse con estos otros-otros. De este modo, el reconocimiento tanto público como privado permite una transformación del contexto sociopolítico e intersubjetivo de los pacientes. El cambio buscado es un proceso que promueva la integración de la experiencia de la tortura, poniendo palabras a las sensaciones y angustias sin nombre, reconstruyendo la subjetividad dañada (Castillo y Morales, 2011).

El reconociendo juega un rol relevante en los grupos, y lo jugó en el contexto de la CNPPT. Ello marca una diferencia relevante con lo ocurrido desde mediados de los '80, en donde ILAS desarrolló grupos terapéuticos con adolescentes, hijos de detenido-desaparecidos y ejecutados políticos en Chile (Becker, Morales y Aguilar, 1994), y fue muy difícil el conformarlos porque los jóvenes no querían adscribirse al rótulo de víctimas, pero luego fue muy difícil cerrarlos, porque el contexto sociopolítico no validaba su experiencia, y el grupo como tal se convirtió en un refugio, del que era difícil despedirse. ILAS desarrolló experiencias grupales con adolescentes en Chile a comienzos de los 90, que fueron inscritos en una investigación-acción desarrollada simultáneamente en Argentina, El Salvador, Guatemala y Chile, que fue ideada originalmente por Ignacio MartínBaró. En los cuatro países se hicieron grupos terapéuticos, buscando articular metodologías y estrategias terapéuticas que pudieran adaptarse a distintos contextos (Becker, Morales y Aguilar, 1994).

El hecho que la CNPPT por su sola constitución legitimara la existencia y condena a la tortura, y así por primera vez hiciera un reconocimiento oficial de parte del Estado de Chile por los daños sufridos, no produjo un cambio en la percepción personal de lo vivenciado. En las traumatizaciones extremas "el reconocimiento tanto en el espacio público como en el espacio terapéutico es indispensable para que ocurra una transformación del contexto sociopolítico e intersubjeteivo de nuestros pacientes" (Castillo y Morales, 2011, p. 175). Así, el espacio terapéutico grupal se convierte entonces en una modalidad adecuada paralos pacientes traumatizados extremos, ya que la subjetividad dañada de estas personas se puede reconstruir en el espacio intersubjetivo que se crea entre los miembros del grupo y los terapeutas (Morales, Castillo, Aguilar y Díaz, 2005).

\section{Los profesionales de la Comisión Nacional sobre Prisión Política y Tortura}

Para la realización de su trabajo la CNPPT puso en marcha una estructura operacional compuesta por un equipo de alrededor de 60 profesionales (abogados, asistentes sociales y psicólogos) que recogieron testimonios a lo largo de todo el país y en consulados y embajadas de Chile en el extranjero. Las personas que depositaron su testimonio en la CNPPT entregaron una ficha con antecedentes relativos a su experiencia de PPT y sostuvieron una entrevista de alrededor de una hora con un profesional de la Comisión con el fin de completar antecedentes acerca de su experiencia. Estos testimonios representaron para las víctimas procesos de recuerdo dolorosos de sus experiencias pasadas, recuerdo que el profesional debía recibir cuidadosamente, creando un ambiente de respeto y confianza, pero sin suscitar expectativas. El estricto respeto de límites y la exigencia de no adoptar posiciones políticas eran reglas que los profesionales debían respetar a fin de mantener la imparcialidad de la Comisión.

En trabajos anteriores se ha analizado desde distintas artistas el impacto que el trabajo en la Comisión tuvo para los profesionales. El primer efecto que se percibe es un impacto emocional, a partir de experiencias emocionales disruptivas e incluso traumáticas que, a partir de la escucha de los declarantes en la Comisión, invadieron a los profesionales requiriendo una significación. Los testimonios de las víctimas, cargados de horror y dolor, impactaron emocional y biográficamente a los profesiones, los que debieron apelar a sus historias personales y familiares para darle lugar y significado a la experiencia de la Comisión en sus tramas biográficas (Cornejo, Morales, KovalskysySharim, en prensa). Para escuchar los testimonios, los profesionales se pusieron en escena a partir del rol de "escucha del Estado"(Buzzoni, 2008), rol determinado desde el mandato de la Comisión (escucha imparcial y recopilación de antecedentes) y desde las significaciones subjetivas atribuidas a esa escucha, en donde el compromiso y el deseo de reparación tensionaron la escucha.

$\mathrm{Al}$ término del trabajo en la Comisión, los profesionales señalan que esta experiencia quedó encapsulada, suspendida, sin posibilidad de ser elaborada, lo que puede estar en relación con la invasión de lo traumático desde los testimonios de las víctimas, ellas mismas silenciadas y suspendidas por años, repitiéndose la imposición de silenciamiento, de la 
prohibición de hablar de esto. La posibilidad ofrecida por la investigación puede entonces comprenderse como permitiendo darle un lugar -en la narración y la propia historia- a esta experiencia (Cornejo, Rojas y Mendoza, 2009).

Considerando el dispositivo de escucha de la Comisión y el propuesto por la investigación, se construyó la noción de "cadena de la escucha" (Cornejo, Rojas y Mendoza, 2009; Cornejo, Brackelairey Mendoza, 2009), el que designa la sucesión de varios dispositivos y formas que va tomando la escucha y la palabra, generando procesos de generación y reconstrucción de lazos subjetivos y sociales que se orientan a deshacer las cadenas del silencio. Esta cadena de la escucha pone en acción posibilidades de transmisión que irían en contra de los riesgos de la repetición. Por esta cadena transita el "secreto" acerca del pasado traumático de nuestro país; se instala desde las víctimas que declararon en la Comisión, pasa por los profesionales que recibieron y recopilaron esos testimonios, continúa en el equipo de investigadores que solicitaron los relatos de vida de esos profesionales y sigue hacia todos aquellos que escuchan las historias de la escucha de la tortura.

\section{Método}

El trabajo que aquí se presenta analiza narrativas provenientes de dos grupos: profesionales que trabajaron enla CNPPT, y pacientes que fueron atendidos en ILAS en la modalidad de grupos terapéuticos posterior a su declaración como testimoniantes en la CNPPT.

\section{Participantes}

En el caso de los profesionales de la CNPPT, fueron en total 22 participantes con quienes se realizaron relatos de vida. El muestreo utilizado para la producción de datos, fue en un inicio un muestreo teórico (Glasery Strauss, 1967), y posteriormente un muestreo intencionado (Flick, 2004), incluyendo profesionales que no habían trabajado en la recepción de testimonios sino en otras labores (generación e informes, transcripciones, ordenamiento y clasificación de información) y que entregaban datos relevantes y significativos respectoa diversas modalidades de escucha de la tortura en la Comisión.El promedio de edad de los profesionales participantes en el estudio es de 41.6 años, con edades que fluctúanentre los 20 y los 60 años. Sus profesiones son abogados, psicólogos, asistentes sociales y sociólogos. En cuanto a las labores realizadas en la Comisión, 13 profesionales recibieron testimonios tanto en Santiago como en regiones; 3 formaban parte del equipo central de la Comisión y además de recibir algunos testimonios realizaron labores de calificación; y 6 realizaron otras labores, relacionadas con la generación de bases de datos y el procesamiento de información.

En el caso de los grupos terapéuticos con declarantes a la CNPPT, fueron realizados 4 grupos, 2 grupos de mujeres y 2 grupos de hombres, con un total de 29 personas. Los grupos de mujeres tuvieron 6 y 8 participantes y losgrupos de hombres 7 y 8 participantes. Las edades de los participantes oscilan entre los 50 y los 70 años, con un promedio de edad de 60 años, en el caso de los hombres y de 55 años en el caso de las mujeres. Pertenecían a un nivel socio-económico medio y medio-bajo y todos residíanen la ciudad de Santiago.

\section{Instrumentos}

En el caso de los profesionales, se realizaron con ellos relatos de vida (Cornejo, Mendoza y Rojas, 2008). Los relatos fueron producidos en una modalidad de 3 encuentros con cada participante, con una duración promedio de 1 hora y media cada uno y espaciados en promedio en un mes. Todos los relatos fueron conducidos por psicólogos clínicos (hombres y mujeres), iniciándolos con la consigna "cuéntame la historia de tu participación en la CNPPT". Los dos primeros encuentros estaban enfocados a desplegar la historia de participación en la Comisión por parte del participante, con un rol menos activo por parte del investigador, de manera a permitir estructurar el relato y la historia desde cada participante. Al inicio de los encuentros 2 y 3 se estipuló un momento para revisar efectos del relato de la propia historia en el encuentro anterior, así como de la lectura de la transcripción entregada. En el tercer encuentro se realizó además una pequeña evaluación del proceso de participación en el estudio y un cierre con cada participante.

Para los grupos terapéuticos se realizarontranscripciones de sesiones y de las reuniones de revisión de lo trabajado en el grupo. Durante la realización de los grupos terapéuticos uno de los terapeutas tomaba nota, tanto de lo dicho como de los emergentes en la dinámica grupal. Todo esto era luego analizado en una reunión de los terapeutas de cada grupo. Una vez al mes, todos los terapeutas de grupos con pacientes derivados desde la CNPPT, traían el material clínico de sus sesiones para ser discutido y analizado con el conjunto del equipo ILAS. 


\section{Procedimiento}

Los participantes de los relatos de vida fueron invitados a la investigación asegurando su libertad de participación. Se realizó un proceso de consentimiento informado asegurando la confidencialidad y resguardo de las informaciones entregadas así como la posibilidad de retirarse de la investigación.

Los relatos de vida fueron recogidos entre los meses de junio y septiembre de 2006, y entre mayo y septiembre de 2007. Todos los relatos fueron recogidos por psicólogos clínicos (5 mujeres y 2 hombres) con preparación teórica y práctica en el enfoque biográfico.

Se incluyeron diversos dispositivos de escucha (Cornejo, Besoaíny Mendoza, 2011) en el proceso de producción y análisis de los relatos como reuniones de inter-análisis, duplas de trabajo, dossier del narrador, intentando dar mayor calidad y densidad a los resultados.

Los relatos fueron grabados integralmente previo consentimiento de los participantes, y entre cada encuentro se le envió la transcripción del encuentro precedente de manera a poder volver sobre este en el encuentro siguiente y suscitar nuevos temas a relatar.

En el caso de los grupos terapéuticos, los pacientes que reciben atención psicológica en ILAS son informados al inicio de esta que ILAS es una institución que realiza investigación a partir del trabajo clínico realizado.Los grupos terapéuticos de los que aquí se da cuenta se realizaron entre los años 2004 y 2006.

Los grupos de mujeres tuvieron una duración promedio de 1 año y medio y los de hombres 9 meses. En todos los casos se realizaron sesiones semanales de una hora y media. Los grupos de mujeres trabajaron con dos terapeutas mujeres $\mathrm{y}$ los grupos de hombres trabajaron con una terapeuta mujer $\mathrm{y}$ un terapeuta hombre.

\section{Análisis de datos}

Los relatos fueron analizados siguiendo dos lógicas analíticas, una singular y otra transversal (Cornejo et al., 2008). La lógica singular se orientó a generar historias de cada participante reordenando cronológicamente los eventos más centrales de sus tramas biográficas, relacionándolos con temas transversales que cruzan estas tramas y permiten ir configurando un cierto sentido o trayectoria. La lógica transversalpermitió mirar todas las historias de los participantes a partir de ciertos ejes temáticos construidos y que permiten comprender desde diversas dimensiones cómo se ha elaborado la experiencia de trabajo en la CNPPT. Ambas lógicas de análisis se apoyaron en métodos provenientes de la groundedtheory (Strauss yCorbin, 1990; Glassery Strauss, 1967) y un análisis para relatos biográficos propuesto por de Villers (1996).

En el caso de los grupos terapéuticos, las transcripciones de sesiones fueron analizadas siguiendo una lógica vertical y horizontal (Pichon-Rivière, 1985). La lógica vertical consistía en revisar la sintomatología y el discurso de cada paciente como un sujeto en el contexto grupal, y la lógica horizontal consistía en revisar los emergentes grupales que son temáticas que ponen miembros del grupo, que se constituyen en los ejes de diálogo en las sesiones. Pichon-Rivière (1985) denomina emergentes grupales del portavoz, cuando un integrante del grupo que en un momento la denuncia el acontecer grupal, las fantasías que lo mueven, las ansiedades y necesidades de la totalidad del grupo (Pichon-Rivière, 1997). Este análisis se realizaba en la dupla de terapeutas, el que luego era llevado al conjunto del equipo ILAS para su discusión y problematización.

\section{Resultados}

Es complejo dar cuenta de los resultados de este trabajo, pues surgen de una comparación y diálogo de dos fuentes de informaciones muy diferentes, como son, por un lado, emergentes -en el sentido descrito por Pichon-Rivière (1985) de dinámicas grupales que se expresan en discursos grupales-de procesos terapéuticos de víctimas de tortura que testimoniaron para el Informe de la CNPPT; y por otro, los relatosde quienes recogieron testimonios en la CNPPTacerca de la experiencia de escucha de la tortura en una investigación. Dado este origen diferente de las informaciones, no se pretende hacer una comparación equivalente de un modo pleno, más aún cuando no todos las personas que dieron su testimonio en la CNPPT solicitaron y recibieron apoyo terapéutico en los grupos de ILAS. El interés es más bien delinear aquellos aspectosque parecieran ponerse en tensión en ambas experiencias, y el lugar que esto puede tener en procesos de elaboración y reparación, a nivel individual y social, de experiencias de traumatizaciones extremas.

Se focalizará el análisis deesta articulación en dos aspectos: las emociones surgidas en los grupos terapéuticos y en los relatos de los profesionales de la CNPPT; y el discurso en su dimensión institucional que marca el que ambas experiencias se hayan realizado asociadas ala CNPPT. 


\section{Las emociones}

\section{a. El miedo y el orgullo asociados al testimonio}

En los grupos terapéuticos, la angustia experimentada por haber realizado el testimonio en la CNPPT, da lugar a un alivio al ser contenida por el grupo. Como contraparte, la angustia expresada por las víctimas al momento de dar su testimonio en la CNPTT, es experimentada por los profesionales, y solo sufre un grado de alivio al ser puesta en el relato en el marco de la investigación. Resulta coherente, aludiendo al concepto de "cadena de la escucha" (Cornejo et al., 2009), que esta pueda ser comprendida como una cadena que encadena, en el sentido que en la medida que las víctimas inician un proceso que atenúa su angustia, esta irrumpe en los profesionales de la CNPPT.

La angustia, transformada en miedo, se ve atenuada por el tema del reconocimiento de la injusticia vivida en quienes fueron detenidos y torturados, y que testimoniaron en la CNPPT. El miedo se diferencia de la angustia respecto del objeto, pues el miedo tiene un objeto de referencia; no obstante, como ya señalaron Lira y Castillo (1991), la amenaza política por su carácter omnipresente despoja al miedo de un objeto cognoscible y deviene en angustia.

En el caso de los profesionales, estos destacan el orgullo por el trabajo realizado en la CNPPT, que es homólogo al orgullo de la restitución de ciudadanía que representa el Informe para las víctimas. Este orgullo es ambivalente en los profesionales, pues se cruza con la rabia asociada a la frustración de expectativas de las políticas reparatorias surgidas de dicho trabajo, y la impotencia frente a la impunidad en que quedan muchos perpetradores de tortura ${ }^{2}$.

En relación al surgimiento del orgullo, señalan los profesionales de la CNPPT y los pacientes de los grupos:

"De todos mis trabajos, quizás ha sido uno de los más bonitos, uno de los que más me ha gustado. Fue duro... me habrá generado angustia en algún momento, pero me sensibilizó”. (Profesional CNPPT).

\footnotetext{
Es importante puntualizar que existen 1.060 procesos legales vigentes, 1.984 procesos legales no vigentes, y 144 procesos en que se dictó sentencia condenatoria ejecutoriada en causas por violaciones de derechos humanos (Informe Marzo 2009, Programa de Derechos Humanos, Ministerio del Interior, Gobierno de Chile).
}

"Me sentí orgulloso cuando me comentaban que habian visto mi nombre en las listas del Informe, porque yo era de un sindicato y no un delincuente". (Paciente ILAS).

"Yo sabía que era importante, pero
después me di cuenta que era histórico,
osea histórico, para la sociedad, para
el país, para el mundo, pero sobre
todo para mi" (Profesional CNPPT).

La sensación de orgullo es evidente en la mayoría de los profesionales de la CNPPT, quienes no sólo sienten satisfacción inicial por la labor realizada, sino que tienden a auto-definirse como sujetos sociales protagonistas de la historia del país a partir de la experiencia de participación en la Comisión. Aquí es donde es posible observar cómo los profesionales tienden a igualarse a lo que los testimoniantes expresaron en los grupos terapéuticos, en donde estos sienten que han recuperado un aspecto de su noción de ciudadanos al ser reconocidos por el Estado chileno, y son capaces de verbalizar sus miedos todavía presentes. Aquí los profesionales también se miran a sí mismos con orgullo, como portadores de un mensaje histórico, pero este pasa también por experimentar miedo por el rol de develar dicha verdad en la sociedad chilena, lo que promueve ansiedades desorganizadoras que alcanzan a generar una distorsión del juicio de realidad.A propósito del miedo experimentado, algunos profesionales de la CNPPT lo expresaron del siguiente modo:

"Pensaba que a lo mejor alguien me
está siguiendo... y me va a quitar el
Informe y no lo podemos entregar"
(Profesional CNPPT).
"Luego de la Comisión, miedo de
ser observada, perseguida, estigma-
tizada por haber trabajado en esto"
(Profesional CNPPT).

Ello contrasta con la atenuación del miedo que los testimoniantes terminan exorcizando en su experiencia terapéutica grupal, dado que este era un espacio protegido por el encuadre terapéutico grupal. Allí, luego de testimoniar la experiencia de tortura mediada por la humillación y el miedo en la CNPPT, y posteriormente al compartir y ser elaborada 
en los grupos terapéuticos, se enfrentan los fantasmas que surgieron de un contexto real de persecución y muerte.

"Sí, ahí por donde no pasaba desde
que me detuvieron...lo hice, no me lo
propuse, pero lo hice, logré caminar
por alli" (Paciente ILAS).

Así el miedo que va abandonando a las víctimas, va surgiendo en algunos profesionales de la CNPPT, siguiendo el mismo curso que la angustia inicial.

\section{b. La frustración y la impotencia asociadas al Informe}

Al parecer, en los profesionales de la CNPPT, empujados por la empatía con el dolor y la legitimidad de las demandas de las víctimas, se produce una frustración en términosno solo de políticas reparatorias y de justicia, sino de los límites de su labor pericial que no incluía un apoyo terapéutico a las víctimas. Así, los profesionales que fueron contratados como escuchas del Estado (Buzzoni, 2008; Cornejo et al., 2009), en algún sentido se transforman en voceros de los testimoniantes, identificándose con ellos y quedando marcados e interpelados por sus historias. Ello también lleva a la paradoja respecto a que en los profesionales de la CNPPT se construyeron identificaciones con la marginalidad de las demandas de las víctimas, a pesar que ellos no formaban parte de esa marginalidad dado que tenían un rol formal inserto en el Estado a través del trabajo en la Comisión. Sin embargo, sí tuvieron vivencias de marginalidad porque su trabajo quedó ubicado en la trastienda, la que se vio reflejada en que los nombres de los profesionales no aparecen en el Informe, ni asistieron a la ceremonia de entrega oficial del Informe. Uno de los profesionales señaló respecto al momento de dar a conocer el Informe:

"Era divertido que las agrupaciones
de familiares nos decian ¿oye y por
qué ustedes no están adentro, por qué
ustedes no fueron? No, no nos invitaron,
porque somos los parientes pobres"
(Profesional CNPPT).

La sensación de rabia también se configura en muchos profesionales desde una noción de "estafa"y "fraude", en el sentido de sentirse engañados en tanto sujetos sociales. El ribete rabioso remite a la impunidad de las violaciones a los derechos humanos, cuestión que no fue parte de los objetivos de la CNPPT, y la calificación de "insuficientes" a lasmedidas reparatorias del Estado chileno, que fueron no sólo de tipo pecuniario, sino además de reconocimiento social. Ese mismo sentimientofue expresado por las víctimas de tortura en los grupos terapéuticos, cuando se refieren a los beneficios pecuniarios emanados del Informe versus la sensación de impunidad en la justicia. La ambivalencia que suscita la aceptación de la reparación, implica que los pacientes delos grupos terapéuticosse muestran al mismo tiempo satisfechos con el reconocimiento desde el discurso institucional y frustrados por la impunidad o por procesos legales tardíos (Castillo y Morales, 2011; Aguilar, Díaz y Gómez, 2005).

\section{"Quedé con amargura al escuchar las medidas de reparación, sentí que fue un fraude en realidad" (Profesional CNPPT).}

\author{
"Y todo para eso, nos volvieron tor- \\ turar" (Paciente ILAS). \\ "Ha sido muy simbólico lo que ha \\ pasado... las vidas no cambian, pero \\ hay una sensación de paz y alivio" \\ (Paciente ILAS).
}

Al mismo tiempo, muchos profesionalesexpresaron su sensación de impotencia desde una necesidad que podría denominarse culpa reparatoria, que los impelía a actuar más allá de su rol, lo que estaba ligado a la percepción, desde su óptica, de escasez de beneficios de las políticas de reparación, así como de la no calificación de los hechos de tortura en algunas personas cuyos testimonios los impactaron. De algún modo, los profesionales aparecen entonces simultáneamente queriendo romper con la pertenencia a la CNPPT, y sintiéndose orgullosos de la labor realizada. Esta misma ambivalencia la experimentan las víctimas, quienes han reexperimentadola sensación de impotencia frente a la impunidad, junto con valorar la verdad y las políticas de reparación.

\section{El discurso institucional}

La organización de la CNPPT implicó la articulación de procesos, funciones y sistemas de roles que tenían como misión lograr determinada producción pericial, y que implicó caracterizar, clasificar, calificar y cuantificar los hechos de 
PPT en Chile durante la Dictadura. Al mismo tiempo, la producción discursiva de la CNPPT, por medio de su Informe final, buscó generar las bases desde donde se desarrollarían las políticas de verdad y reparación del Estado chileno en relación a los actos de PPT ocurridos durante 1973-1990. Estos eran actos a los que, por primera vez en 30 años, se les otorgaba reconocimiento oficial desde el Estado, como hechos injustos y abusivos por parte de agentes del Estado, promoviendo un nuevo contexto para la articulación de las subjetividades de los chilenos en relación a esta temática.

\section{a. Confiabilidad y culpa en las instituciones}

Uno de los aspectos a pensar desde la mirada en lo institucional, es cómo las víctimas que han requerido atención psicológica debido a los daños sufridos, han hecho sus demandas en instituciones cuya confiabilidad estaba dada por la trayectoria y compromiso en la atención de ese tipo de problemas, como es el caso de ONGs de derechos humanos y el programa PRAIS (programa de reparación y atención integral en salud y derechos humanos perteneciente al Ministerio de Salud). En las derivaciones por atención que realizó la CNPPT, lo hizo sugiriendo directamente ciertas instituciones, desconocidas para estas personas. En este sentido, para los pacientes de los grupos terapéuticos, llegaron solo confiando en que el Estado chileno viabilizaba su ayuda.

Esto es muy relevante porque también la confianza permitió a las víctimas desculpabilizarse del daño sufrido por agentes del Estado. Pero, como contraparte, los profesionales de la CNPPT, como representantes del Estado, tendieron a culpabilizarse de la insuficiente reparación.

\section{b. Privatización del daño y discurso público}

El reconocimiento del ejercicio de la tortura por parte del Estado chileno, implica la transformación de lo íntimo/ privado en social/público, y ello es experimentadocomo un aspecto a valorar, como un aporte a la salud mental de los testimoniantes, considerando que estos hechos fueron negados y silenciados sistemáticamente en el espacio social. Al mismo tiempo, existe gratificación en el ejercicio de escuchar y así dar lugar a la palabra, permitiendo poner en el espacio público, experiencias que para ser significadas, requieren de la mirada de otros para su elaboración. Así ocurrió en los grupos terapéuticos, donde las personas víctimas de tortura progresivamente fueron dando valor a esa palabra expresada en el grupo, transformando su relación con su entorno familiar y social al develar su sufrimiento "intimo". Por su parte, los profesionales de la CNPPT se hacen partícipes de esa transformación, pero con un desplazamiento de "lo público" a "lo privado", pues el Informe de la CNPPT es público, pero los testimonios individuales quedaron en reserva, en el espacio privado creado entre los profesionales y las víctimas.

Es posible entender en este sentido que el Informe permite la transformación de la privatización del daño (Riquelme y Cruz, 2005) en discurso de denuncia pública, en tanto se pierde la individualidad en el Informe sólo expresada en los nombres de los testimoniantes, no así en sus experiencias específicas, al modo de un "secreto público" (Cornejo et al., en prensa). No obstante esto, los profesionales sí son depositarios de esas experiencias específicas, ya que la modalidad de recepción de testimonios implicaba justamente el contar la experiencia a un profesional. Los profesionales de la CNPPT y las víctimas de tortura muestran itinerarios contrapuestos respecto del portar un secreto público:

\begin{abstract}
"Después de hablar lo ocurrido y desde que salió el Informe, siento que me ven distinto los vecinos, ellos vieron cuando me llevaron al estadio... bueno y ahora hablé con mi hijo y le conté lo que pasó allá" (Paciente ILAS).
\end{abstract}

\section{"Caminaba como extraña. Que yo sentía una sensación extraña como un extraterrestre, como que llevaba una historia y que los demás, como una historia media secreta y los demás en la calle, compraban, fumaban, compraban diarios, como que la vida iba en otra velocidad..." (Profesional CNPPT).}

Junto al valor de lo público en algunos profesionales de la CNPPT, resalta el reconocimiento en el establecimiento de la verdad y cómo esta transforma lo sociopolítico, pero junto con esto se instala -como ocurriera antes con las víctimas- la noción de amenaza presente y permanente (Lira y Castillo 1991), distorsionando la realidad, fantaseando el que podría volver a ocurrir un golpe de Estado, y la consiguiente represión política con violaciones de los derechos humanos. Y frente a esta fantasía de amenaza algunos profesionales de la CNPPT tomaron resguardos frente a peligros lejanos a la realidad chilena actual.Esto incluso lleva a algunos profesionales a tener un protocolo para ese momento: 
"Nosotros ya habíamos acordado irnos del país si pasaba algo" (Profesional CNPPT).

\section{c. La transferencia}

En la transferencia de las víctimas hacia los terapeutas en los grupos, y de los profesionales de la CNPPT hacia los investigadores que recogieron sus relatos en la investigación, sobresalen la idealización de estos. Los terapeutas y los investigadores, en función de ocupar unlugar confiable y equidistante, son al mismo tiempo significados como mensajeros hacia el Estado, pero no formando parte este.

En este sentido, según el relato de los profesionales dela CNPPT, así como en la experiencia de los terapeutas, las víctimas tienden a asignar la bondad, y desde ella la idealización del lugar de "reparador"de los terapeutas y profesionales de la CNPPT como sujetos autónomos e independientes. Sujetos autónomos en el sentido en que se desvinculan como parte de una política del Estado, o de una acción en el marco de una institución, y sus acciones son interpretadas como acciones personales privadas. Esto es relevante, porque en el caso de los grupos terapéuticos,se trató en específico de un programa, que contó con financiamiento gubernamental; $y$ en el caso de la investigación, la realiza una universidad con financiamiento de un fondo de investigación del Estado de Chile.

En el caso de los terapeutas, es habitual considerar esta transferencia positiva que tiende a ser idealizada en el vínculo terapéutico, y por ello es considerada como parte del proceso, y los terapeutas la registran, agradecen, al mismo tiempo que la comprenden como parte del proceso terapéutico, más que darle credibilidad del lugar proyectado. En el caso de los profesionales de la CNPPT, también ellos pudieron ocupar por un momento ese lugar idealizado, rotulado como escuchas del Estado. Y si bien ocupar ese espacio puede ser gratificante por el eventual agradecimientode las víctimas, al autonomizarse de su lugar social pudo llevar a desventuras del mismo, como son los sentimientos culposos de muchos profesionales atribuyéndose responsabilidades que nunca tuvieron en la calificación de los $\operatorname{casos}^{3}, \mathrm{o}$ al no poder desarrollar por el rol prescrito, acciones sociales reparatorias más allá del rol de "escucha".

La calificación de los hechos en que se hizo convicción de los hechos de detención y tortura fue una prerrogativa exclusiva de los Comisionados, que fueron los que dirigían la CNPPT.
Como una forma de lidiar con este dilema en los profesionales de la CNPPT, de ser parte de la escucha del estado y de sus políticas reparatorias, y simultáneamente,ser parte de la escucha de las víctimas hacia el Estado, con las intensidades de sus demandas incumplidas, se produce la identificación ambivalente desde un lugar que busca referentes colectivos. Por ello, al referirse a sí mismos señalan:

"Voy a seguir hablando de nosotros (...) puede ser yo, puede ser nosotros, porque claro, finalmente eran pensamientos compartidos y sentimientos compartidos..."(Profesional CNPPT).

\begin{abstract}
"Es como un dolor ciego, como que sé que no tengo nada que hacer, sé que no le voy a devolver la tranquilidad a esa gente, que lo que sufrieron los va a marcar de por vida, y el hecho de que ellos sufran eso, que lo van seguir sufriendo de por vida, amí me ocasiona un dolor" (Profesional CNPPT).
\end{abstract}

\section{Conclusiones}

El sufrimiento de las víctimas de prisión política y tortura y las dinámicas psíquicas asociadas al mismo, son posibles de ser observados en los grupos terapéuticos con pacientes declarantes de la Comisión, en donde simultáneamente se quiere expulsar la vivencia de humillación propia de la tortura, la que también se valida como condenable por el testimonio en la CNPPT, lo que implica una ambivalencia a la hora de hacerse cargo de esta vivencia. Así, el tomar contacto con las experiencias de la tortura se vive como disruptivo, pero simultáneamente, al poder expresarlo en los grupos, existe un alivio de esa vivencia. El reconocimiento del sufrimiento en el grupo, si bien tiene un rol fundamental en la reparación de los vínculos de las personas, adquiere mayor fuerza cuando dicho sufrimiento ha tenido un reconocimiento por parte del Estadode Chile, en este caso a través de la CNPPT y las políticas reparatorias que desde allí emanaron.

Del relato de la experiencia de los profesionales de la CNPPT no sólo queda claro que ellos vivieron un impacto biográfico (Cornejo et al., en prensa), sino que puede constatarse a partir del análisis de sus relatos una identificación ambivalente, la que parece obedecer a un mecanismo utilizado para tolerar el impacto emocional que tiene la 
escucha de un testimonio tras otro, que van mostrando el horror vivido por las víctimas en su detención. Se trata de una "identificación ambivalente" con las víctimas, pues se alude a un proceso en el cual muchos profesionales de la CNPPT se identificaron con el sufrimiento de los torturados $\mathrm{y}$ con sus demandas de reparación y justicia, y al mismo tiempo quisieron demarcarse de su rol de funcionario del Estado chileno. La identificación con el sufrimiento, podría señalarse como un proceso esperable, no obstante el calificativo de ambivalente adquiere sentido en tanto desde el rol, los profesionales fueron funcionarios del Estado, y simultáneamente parecieron establecer una distancia y desapego con el rol ejercido.

La identificación ambivalente de los profesionales de la CNPPT, se hizo visible tanto en las intensas emociones asociadas a los testimonios escuchados en la Comisión, como en el discurso institucional de reconocimiento de dicho rol desde el Estado, implicando una suerte de apropiación del testimonio de las víctimas por parte de los profesionales. Como estos testimonios están atravesados por lo traumático de revisitar el horror de la tortura y al mismo tiempo el alivio de expresarlo, el proceso de apropiación queda también teñido por esa ambivalencia.

Así, la identificación ambivalente no solo parece inevitable, aunque necesaria de elaborar, sino que también entrega luces de la dificultad no solo de estos profesionales, sino quizás de toda la sociedad chilena, y tal vez de otras sociedades, que tal vez quieren y sienten que no pueden escuchar acerca de a tortura, porque temen que les ocurra lo mismo que a las víctimas, tal como señalan Cárdenas et al. (2011). Como dice Galeano (2005): "la democracia tiene miedo de recordar y el lenguaje tiene miedo de decir" (p. 83), y quizás aquellas emociones alivian al hablar, pero frustran el alcance de la palabra.

El Informe de la CNPPT como discurso hegemónico y público promueve el reconocimiento de las violaciones de los derechos humanos cometidas por agentes del Estado de Chile. La contención de este reconocimiento solo puede hacerse desde el vínculo con un otro disponible que contenga, lo que implica un desasosiego empático (La Capra, 2005). El desasosiego empático no solo es útil para comprender la vivencia de los profesionales, sino también para pensar cómo la sociedad chilena está avanzando en la escucha de la tortura, y qué lugar tiene esta en la memoria histórica del país. En esa línea puede plantearse que el dilema es entre el abuso de memoria (Todorov, 1995) y el deber de memoria (Levi, 1997), en el sentido de buscar un culto a la memoria sin grietas, uniforme y homogéneo y radicada en la conmemoración obsesiva del pasado, o más bien buscar una memoria ejemplar, que permita sacar una lección para las prácticas sociales del presente y del futuro.

Los dilemas de la memoria y la elaboración de experiencias traumáticas podrían quedar atrapados en las víctimas, solo como una experiencia terapéutica privada, sin romper el lugar de la privatización del daño (Lira, Becker y Castillo, 1991), si no es posible constituirla en una huella de memoria, que alimente el presente. Por ello, aun cuando la psicoterapia grupal con víctimas de tortura, sea un formato de trabajo especialmente nutritivo en su capacidad de contención emocional y empatía de la experiencia de tortura, adquiere especial fuerza cuando existe un discurso social que condena lo ocurrido. Este discurso social construye memoria a través de las Comisiones de Verdad y Reparación, y cuando es construido en base a testimonios entregados a un profesional en una relación diádica, como Escucha del Estado como un otro disponible. Luego, los investigadores al interesarse por la experiencia de los profesionales pasan a formar parte de esta cadena de la escucha, transformándose en otro-otro disponible. Como señala una profesional de la CNPPT refiriéndose a los investigadores:

"Yo debo agradecer, porque era infor-
mación que uno tenía así contenida
por mucho tiempo... y no se puede
compartir con cualquiera tampoco"
(Profesional CNPPT).

La ambivalencia de la escucha de la tortura en Chile, implica la apertura a escuchar y al mismo tiempo el temor de escuchar, de ponerse en el lugar de las víctimas, de escuchar su dolor, su impotencia, su miedo, su horror, y no poder elaborarlo. Esto no es posible hacerlo solos, sino solo juntos, colectivamente, porque, tal como dice Carlos Cerda (2002) en su libro La Casa Vacía: "Si no hay oídos para el dolor, no hay oído verdadero para nada. Todos somos vulnerables a la desgracia. El único consuelo es saber que nuestro lamento será escuchado por un corazón solidario" (p. 478). En la medida en que avanzan los procesos de construcción de la memoria histórica, se posibilita que se multipliquen los otros disponibles para escuchar acerca de la tortura y el horror ocurridos en Chile, aunque siempre esta escucha estará teñida por la ambivalencia que genera.

\section{Referencias}

Aguilar, M.I., Díaz, M., y Gómez, E. (2005). Análisis de los efectos psíquicos asociados al Informe de la CNPPT en la elaboración de lo traumático. Mesa Redonda: Impacto psicosocial del Informe de la 
Comisión de Prisión Política y Tortura en Chile: Estrategias terapéuticas y desafios éticos. IV Congreso Mundial de Psicoterapia: TheWorld Council for Psychotherapy (WCP), Buenos Aires.

Barreto, I.,y Borja, H. (2007). Violencia política: algunas consideraciones desde la psicología social. Revista Diversitas Perspectivas en Psicología, 3, 109-119.

Becker, D., Morales, G., y Aguilar, M.I. (Eds.) (1994). Trauma psicosocial y adolescentes latinoamericanos: Formas de acción grupal. Santiago: CESOC.

Bettelheim, B. (1981). Sobrevivir. El holocausto una generación después. Barcelona: Grijalbo.

Buzzoni, M.E. (2008). Escuchar desde el Estado: significados asociados a la relación establecida entre los profesionales y las personas que concurrieron a declarar a la Comisión Nacional sobre Prisión Política y Tortura. (Tesis no publicada de Magister para la obtención del título de Magíster en Psicología Clínica). Escuela de Psicología, Pontificia Universidad Católica de Chile.

Cárdenas, M., Páez, D., Bilbao, M., Arnoso, M., Asún, D.,y Fernández, G. (2011). Collective processes, social and psychological well-being: The psychosocial impact of the Chilean "Truth and Reconciliation" and "Political Imprisonment and Torture"commissions. (Manuscrito sometido para publicación).

Castillo, M.I. y Díaz, M. (2007, Noviembre). Terapia grupal con mujeres víctimas de violencia del Estado. Ponencia presentada en el VII Congreso Nacional de Psicología, Santiago, Chile.

Castillo, M.I. y Díaz, M.(2010, Noviembre). Tortura Sexual y Abordaje Terapéutico Grupal. Ponencia presentada en el XIX Encuentro Latinoamericano sobre el pensamiento de Winnicott, Santiago, Chile.

Castillo, M.I., y Morales, G. (2011). Psicoterapia grupal y tortura. En G. Morales, B. Ortúzary E. Thumala (Eds.), Psicoterapia psicoanalítica de grupo y vínculos (pp. 171-189). Santiago: Orjikh Ediciones.

Castillo, M. I. (2009). Transmisión de la Violencia y Memoria Social. Revista Praxis, 15, 99-114.

Cerda, C. (2002). Tres Novelas: Morir en Berlin; Una casa vacía; Sombras que caminan. Santiago de Chile: Alfaguara.

Cornejo, M., Besoaín, C., y Mendoza, F. (2011). Desafíos en la Generación de Conocimiento en la Investigación Social Cualitativa Contemporánea [94 párrafos]. Forum: Qualitative Social Research, 12(1), Art. 9, http:// www.qualitative-research.net/index.php/fqs/article/view/1527/3141.

Cornejo, M., Brackelaire, J. L., y Mendoza, F. (2009). Des chaînes du silence à la chaîne de l'écoute. Cahiers de Psychologie Clinique, 32, 205-231.

Cornejo, M., Mendoza, F., y Rojas, R.C. (2008). La investigación con relatos de vida: pistas y opciones del diseño metodológico. Psykhe, 17, 29-39.

Cornejo, M., Morales, G., Kovalskys, J., y Sharim, D. (en prensa). La escucha de la tortura desde el Estado: la experiencia de los profesionales de la Comisión Nacional sobre Prisión Politica y Tortura en Chile. Universitas Psychologica.

Cornejo, M., Rojas, R., y Mendoza, F. (2009). From Testimony to Life Story: The Experience of the Professionals of the Chilean National Commission on Political Imprisonment and Torture. Peace y Conflict: Journal of Peace Psychology, 15, 111-133.
Cornejo, M., Rojas, R. C., Buzonni, M. E., Mendoza, F., Concha, M., y Cabach, C. (2007). Prisión política y tortura: Desde las intervenciones psicosociales a las políticas de reparación. Persona y Sociedad, 21, 59-81.

de Villers, G. (1996). Le récit de vie comme approche de recherche-formation. In D. Desmarais, J. M. Pilon (Coord.) (1996). Pratique des histoires de vie. Au carrefour de la formation, de la recherche et de l'intervention (pp. 107-134). Paris: L'Harmattan.

Flick, U. (2004). Introducción a la investigación cualitativa. Madrid: Ediciones Morata.

Galeano, E. (2005). Patas arriba: La escuela del mundo al revés. Buenos Aires: Catálogos.

Glaser, B. y Strauss, A. (1967). The discovery of Grounded Theory, strategies for Qualitative Research. New York: Aldine.

Hamber, B. (2000). Repairing the irreparable: Dealing with double-binds of making reparations for crimes of the past. Ethnicity and Health, 5, 215-226.

Informe de la Comisión Nacional sobre Prisión Política y Tortura (2004). Recuperado desde http://www.bcn.cl/bibliodigital/dhisto/lfs/Informe. pdfLaCapra, D. (2005). Escribir la historia, escribir el trauma. Buenos Aires: Nueva Visión.

Levi, P. (1997). Le devoir de mémoire. Paris: Mille et Une Nuits.

Lira, E.,y Castillo, M. I. (1991). Psicología de la amenaza política y del miedo. Santiago: ILAS/CESOC.

Lira, E., Becker, D., y Castillo, M. I. (1991). Derechos humanos: Todo es según el dolor con que se mira. Santiago, Chile: ILAS.

Martín-Baró, I. (1988). La violencia política y la guerra como causa del trauma psicosocial. Revista de Psicología de El Salvador, 28, 123-141.

Morales,G.; Castillo, M.I.; Aguilar, M.I. y Díaz, M. (2005, Agosto). Abordaje Terapéutico Grupal y Tortura. Ponencia presentada en el IV Congreso Mundial de Psicoterapia, Buenos Aires, Argentina.

Pichon-Rivière, E. (1985). El proceso grupal. Del psicoanálisis a la psicología social. Buenos Aires: Nueva Visión.

Pichon-Rivière, J. (1997). Diccionario de términos y conceptos de psicología y psicología. Buenos Aires: Nueva Visión.

Puget, J. (2006). Violencia social y psicoanálisis: De lo ajeno estructurante a lo ajeno-ajenizante. En J., PugetyR. Kaes. (Eds.), Violencia de Estado y psicoanálisis (pp. 25-56). Buenos Aires. Lumen.

Riquelme, J., y Cruz, G. (2005). Impacto de la Comisión Nacional sobre Prisión Política y Tortura en Chile.RevistaVirtu@l ILAS, 4. Recuperado desde http://www.ilas.cl/revi 4.html

Strauss, A., y Corbin, J. (1990). Basics of qualitative research: grounded theory procedures and techniques. Newbury Park: Sage.

Todorov, N. (1995). Les abus de la mémoire. Paris: Arléa Poches.

van der Merwe, H. (2002). National narratives versus local truths: The truth and reconciliation commission's engagement with Duduza. In D. Posely G. Simpson (Eds.), Commissioning the past: Understanding South Africa's truth and reconciliation commission (pp. 269-281). Johannesburg: Witwatersrand University Press.

Winnicott, D.W. (1954). Aspectos Metapsicológicos y clínicos de la regresión dentro del marco psicoanalítico. En D.W. Winnicott, Escritos de Pediatría y Psicoanálisis. Barcelona: Editorial Laia.

Winnicott, D.W. (1956). Preocupación Maternal Primaria. En D.W. Winnicott, Escritos de Pediatría y Psicoanálisis. Barcelona: Editorial Laia. 